\title{
Paediatric radiology from a psychosocial lens
}

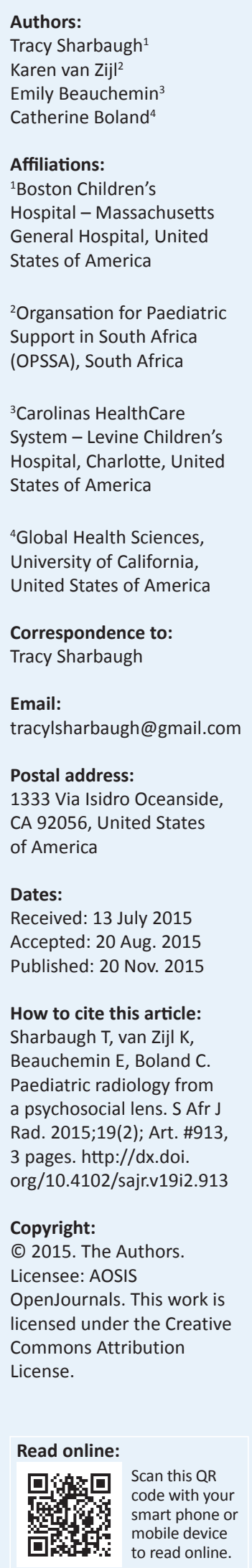

Globally, hospitals and medical centres have a reputation of causing individual patients an increased level of anxiety, stress and pain owing to their foreign environments, intimidating examinations and rigorous treatments. Because of children's cognitive and developmental levels of understanding and communication, they are more susceptible to increased levels of stress and trauma associated with medical examinations and hospitalisation. Certified Child Life Specialists (CCLSs) are professionals trained in child development and family systems expertise who work directly with children and families to meet their psychosocial and emotional needs in order to help them overcome some of life's most challenging events, including hospitalisation, illness and trauma. This article aims to address the history of the child life profession and the significance of child life in a paediatric imaging unit, and to discuss the current and future status of psychosocial services in South Africa.

\section{History and overview of the child life profession}

Historically, in the first half of the twentieth century, infants and children who required medical interventions were placed in institutionalised medical settings and isolated from their caregivers and families. Research on medical care during this time showed alarming rates of infant and toddler sensory deprivation, an absence of sufficient human contact resulting in increased levels of stress, and a disturbingly high rate of premature infant death. ${ }^{1}$ Hospitalised children and adolescents face emotional disturbances including, but not limited to, post-traumatic stress, anxiety and depression. ${ }^{2,3,4}$ To address these issues and provide higher quality care for children facing chronic illnesses, hospitals employed teachers, play and recreational therapists, and other professionals to provide psychosocial and emotional support services. In 1965, a group of these teachers and therapists came together in Massachusetts, United States of America (USA), to share stories of both triumph and hardship, forming a group that is known today as the Child Life Council (CLC). ${ }^{1,5}$

In 2006, the American Academy of Pediatrics (AAP) stated that Certified Child Life Specialists (CCLSs) 'have become a standard in most large paediatric centers, and even on some smaller paediatric inpatient units'. ${ }^{1}$ Even more notable is that the AAP officially recognised child life professionals as members of the multidisciplinary team, integral to family-centred care and bestpractice models. ${ }^{1,6}$

The mission of the CLC in 1965 was to change the culture of medical environments to be more child and family-centred. Today the mission stands to continue to enhance optimal patient- and family-centred care through advocacy, education, play, assessment, intervention and policy building. ${ }^{1,7}$ The CLC intends that all CCLSs should 'strive to reduce the negative impact of stressful or traumatic life events and situations that affect the development, health and well-being of infants, children, youth and families by embracing the value of play as a healing modality ${ }^{\prime 1,7}$

\section{Significance of child life services and specific research in paediatric imaging}

Traditionally, child life services focused on providing support for inpatients; however, in recent years, CCLS have adapted services to accommodate acute outpatient medical settings such as diagnostic imaging. Patients, families and staff alike report that radiological procedures are especially challenging for paediatric patients because they often are invasive and require the child to be still for extended periods of time ${ }^{7}$ this results in heightened levels of anxiety and stress in both children and parents. Often, medical professionals have to revert to sedation or forced restraint to complete basic radiological procedures. Dean et al. reported that forcible interventions, such as restraint, implemented by medical personnel impair admission outcomes and the therapeutic relationship between the child and medical personnel. ${ }^{2}$ CCLS, alongside 
the medical team, work to decrease this stress in children by assessing their developmental and cognitive understanding of procedures and then providing procedural preparation and medical play: techniques used to explain medical information to children using developmentally appropriate language. ${ }^{5,6,7}$ Simultaneously, CCLS work to increase coping by providing emotional support, distraction and relaxation techniques such as imaginary play, guided imagery, and progressive muscle relaxation. Through these individually designed supportive services, children are more able to comply with examination requirements, complete clear diagnostic imaging and take an active role in their healthcare, whilst minimising potential trauma and stress. $5,6,7$

With healthcare costs rising globally, psychosocial services such as child life programmes have been targeted during budget cuts because they are traditionally viewed as non-revenue producing programmes. However, recent exploratory research has been conducted with initial results indicating that child life services reduce costs associated with imaging for patients and families. At Children's National Health System in Washington, DC, USA, CCLSs employed in radiology departments designed and implemented 'MR-I Can Do It', a programme aimed to reduce the rates of paediatric anaesthesia sedation for children 3-18 years old through child life preparation and emotional support. The programme reported that, whilst most adults perceive claustrophobia as the main stressor related to magnetic resonance imaging (MRI) scanning, children like to hide in small spaces for fun (e.g. hide and seek). Instead, children described the unfamiliarity of a new environment, large equipment and intensity of sounds as the most stress-inducing factors related to their MRI. To minimise these fears, CCLS created educational preparation material that is distributed online and by email to parents and children using real-life pictures and child-friendly language describing what the child would experience. The educational material also provides age-specific tips on ways for parents to best support their child before and during the scan. CCLS used desensitisation techniques by instructing parents and children to pre-emptively play a game while listening to MP3 files of MRI recordings, thus minimising the related anxiety and fears. Statistical analysis of the MR-I Can Do It programme reported that, for $94 \%$ of children who participated in the programme, diagnostic quality MRI images were successfully obtained at the first time without the use of sedation. ${ }^{8}$ No demographic variances including age, gender, type of study etc. were found to be statistically significant during the analysis. Ensuing results also indicated that the programme reduced time for patients and families at hospital and increased overall patient satisfaction.

\section{Current status of child life in South Africa}

Medical care for children is a human right. South Africa's population consists of more than 18.6 million children under the age of $18 .{ }^{9}$ Despite research findings on the negative impact of illness, hospitalisation and stress in children, the level of psychosocial services available to patients in South Africa is minimal. Currently in South Africa, it is rare for a hospital to render services such as play and expressive activities in support of normal development. Barriers to providing psychosocial care include a lack of funding, resources, professional experience and training, and overall awareness regarding the need and value for psychosocial care. ${ }^{10}$ Despite barriers and challenges, influential organisations and individuals are collaborating to make positive changes to enhance and optimise children's and families' experiences with healthcare.

Psychosocial services are currently formally rendered in two hospitals in South Africa: Red Cross War Memorial Children's Hospital and the Netcare Unitas Hospital. Outside the hospital, psychosocial professionals provide support to children with health issues within private practice and community settings on a limited basis. Nonprofit organisations, such as Childhood Cancer Foundation South Africa (CHOC) and Umduduzi - Hospice Care for Children, employ social workers and auxiliary social workers who implement psychosocial services to paediatric haematology-oncology patients and palliative patients. ${ }^{10}$ These programmes both serve a minute percentage of the paediatric population in South Africa; accordingly, the present paper aims to increase awareness of the importance of standardising psychosocial support in all medical institutions in South Africa.

\section{The future of child life in South Africa}

With the aim of furthering paediatric psychosocial services in South Africa, the Organisation for Paediatric Support in South Africa (OPSSA) hosted two one-day seminars in 2011 and 2014. Additionally, OPSSA hosted the first International Interdisciplinary Academic Conference in Johannesburg in conjunction with Netcare in 2013. In 2014, Karen van Zijl, President of OPSSA, became the first South African citizen to obtain her certification as a Certified Child Life Specialist. OPSSA is currently in discussion with tertiary institutions about the development of academic courses in paediatric psychosocial support with the support of CLC in the USA. The future vision of child life and psychosocial services in South Africa is to register child life workers with the Health Professions Council of South Africa (HPCSA).

\section{Conclusion}

Programmes that foster psychosocial and emotional growth of paediatric patients build resiliency and increase patient coping skills, whilst decreasing the stress and trauma of the hospital setting. Appropriate preparation and support for diagnostic testing decreases the need for sedation, reduces the recovery time of patients and families and increases overall patient satisfaction. Globally, children deserve to be provided with psychosocial support during hospitalisation. South Africa is an ideal country for 
continuing to implement these invaluable services. With the current initiatives taking place, South Africa aims to continue to expand these psychosocial support services.

\section{Acknowledgements Competing interests}

The authors declare that they have no financial or personal relationships which may have inappropriately influenced them in writing this article.

\section{Authors' contributions}

T.S. (Boston Children's Hospital - Massachusetts General Hospital) wrote 'History and overview of the child life profession' and 'Significance of child life services and specific research in paediatric imaging'. E.B. (Carolinas HealthCare System-Levine Children's Hospital) contributed the 'Current status of Child Life in South Africa and internationally; K.v.Z. (Organsation for Paediatric Support in South Africa) contributed the 'Future of Child Life in South Africa'; and C.B. (Global Health Sciences) contributed to the document with inserted additions and edits throughout the article.
All authors contributed to the comprehensive review and editing process of the document.

\section{References}

1. Child Life Council. Overview of child life. 1998-2015. c2015 [cited 2015 June 1] Available from http://www.childlife.org

2. Dean AJ, Duke SG, Scott J, Bor W, GeorgeM, McDermott BM. Physical aggression during admission to a child and adolescent inpatient unit: Predictors and impact on clinical outcomes. Aust N Z J Psychiatry. 2008;42:536-543. PMID: 18465381, http://dx.doi.org/10.1080/00048670802050587

3. Jansen GJ, Dassen TWN, Burgerhof JGM, Middel B. Psychiatric nurses' attitudes toward inpatient aggression: Preliminary report of the development of attitude towards aggression scale (ATAS). Aggress Behav. 2006;32:44-53. http://dx.doi. org/10.1002/ab.20106

4. Mackenzie A. Everybody stay calm. Victoria: Global Publishing Group; 2014.

5. Thompson RH, Stanford G. Child life in hospitals: Theory and practice. Springfield, IL: Charles C. Thomas; 1981.

6. Brown C, Chitkara MB. Policy statement: Child life services. Paediatrics. 2014;1.

7. Thompson RH. The handbook of child life: A guide for pediatric psychosocial care. Springfield, IL: Charles C. Thomas; 2009.

8. Sze RW. The economic value of a child life program for non-sedated MR imaging. Technical research report to the Child Life Council. c2014 [cited 2015 June 26]. Available from http://www.childlife.org/files/MR\%20Nonsedate\%20Tech\%20 Report\%20May\%202014.pdf

9. Hall K, Meintjes H. Demography - children in South Africa. Children count: Statistics on children in South Africa. c2014 [cited 2015 June 28]. Available from: $\mathrm{http}: / /$ www.childrencount.ci.org.za/indicator.php?id=1\&indicator=1

10. Child Life Council. International summit on pediatric psychosocial services: A global perspective on play and psychosocial care for children in hospitals; 2014 May 25-27; New Orleans. 